\title{
Correction to: Online pulse interleaving task scheduling for multifunction radar
}

\author{
Haowei Zhang ${ }^{1} \mathbb{D} \cdot$ Junwei Xie ${ }^{1}$ Q Qiyong $\mathrm{Hu}^{1,2} \cdot$ Zhaojian Zhang $^{1,3} \cdot$ Binfeng Zong ${ }^{4}$
}

Published online: 2 May 2019

○) Springer Science+Business Media, LLC, part of Springer Nature 2019

\section{Correction to: Journal of Scheduling https://doi.org/10.1007/s10951-018-0580-2}

The original publication of this article contained a number of grammatical errors. Unfortunately, an incorrect version of the file that did not include some final language editing was inadvertently processed by the typesetter. In many occurrences, words such as "durations", "analyses", "comprises" and "ratios" were incorrectly published as duration, analysis, composed, and ratio.

The original article has been corrected.

Publisher's Note Springer Nature remains neutral with regard to jurisdictional claims in published maps and institutional affiliations.

The original article can be found online at https://doi.org/10.1007/ s10951-018-0580-2.

$\triangle$ Haowei Zhang

zhw_xhzf@163.com

1 Air and Missile Defense College, Air Force Engineering University, Xi' an 710051, Shaanxi, People's Republic of China

2 Present Address: Unit 94873, PLA, Fuzhou 350300, Fujian, People's Republic of China

3 Present Address: Air Force Early Warning Academy, Wuhan 430012, Hubei, People's Republic of China

4 Unit 94710, Wuxi 214000, Jiangsu, People's Republic of China 